\title{
Complex Packaging Structures Based on Wood Derived Products: Actual and Future Possibilities for 1-Way Food Packages
}

\author{
Gustaaf Schoukens ${ }^{1}$, Christopher Breen ${ }^{2}$, Marco Giacinti Baschetti ${ }^{3}$, Graziano Elegir ${ }^{4}$, Mika Vähä-Nissi ${ }^{5}$, \\ Qiuyun Liu ${ }^{6}$, Sanne Tiekstra ${ }^{7} \&$ Peter Simon ${ }^{8}$ \\ ${ }^{1}$ Department of Textiles, Ghent University, Technologiepark 907, B-9052 Zwijnaarde (Gent), Belgium \\ ${ }^{2}$ Materials and Engineering Research Institute, Sheffield Hallam University, City Campus, Howard Street, \\ Sheffield S1 1WB, UK \\ ${ }^{3}$ Università di Bologna, Dipartimento di Ingegneria Civile, Chimica, Via Risorgimento 2, 40136 Bolgna, Italy \\ ${ }^{4}$ INNOVHUB, Via Guiseppe Colombo 83, 20133 Milano, Italy \\ ${ }^{5}$ VTT Technical Research Centre of Finland, P.O. Box 1000, FI-02044, Finland \\ ${ }^{6}$ Biocomposite Centre, Bangor University, LL57, 2UW Bangor, United Kingdom \\ ${ }^{7}$ BUMAGA NV, Ysselburcht 3, BS-Arnhem-Postbus 5486, 6802 EL Arnhem, Netherlands \\ ${ }^{8}$ Slovak University of Technology, Faculty of Chemical and Food Technology, Radlinského 9, 81237 Bratislava, \\ Slovakia \\ Correspondence: Gustaaf Schoukens, Department of Textiles, Ghent University, Technologiepark 907, B-9052 \\ Zwijnaarde (Gent), Belgium. E-mail: Gustaaf.Schoukens@UGent.be
}

Received: August 21, 2014 Accepted: September 5, 2014 Online Published:September 23, 2014

doi:10.5539/jmsr.v3n4p58 URL: http://dx.doi.org/10.5539/jmsr.v3n4p58

\begin{abstract}
Paper and paperboard are the most widely used packaging materials for both food and non-food products. Because they are composed of highly porous cellulose networks, they readily absorb moisture in high humidity environments or when in contact with liquid or high moisture foods. Therefore they are often coated with hydrophobic coating materials such as polyethylene (PE) to improve their water-resistant properties. One of the major uses of such hydrophobic material coated paperboard is a disposable single-use paper cup with or without a lid. Today, the paper-based materials are coated with a thin layer of a petroleum derived plastic, mostly polyethylene, which has provided the cups and other packaging solutions with the required barrier property and water resistance. Hence, the ongoing challenge is to coat the paper with a biobased, hydrophobic polymeric material which must be repulpable or otherwise biodegradable in most of the environments considered.

Many interesting developments are already known for the manufacturing of cellulose-based products, such as microfibrillated celluloses (MFC's) or modified celluloses, usable in the paper packaging industry. Paper and paperboard in combination with Green-Polyethylene, MFC's and polyhydroxyalkanoates (PHA's) seems to be the most promising solution for the packaging industry in the near future and the development of the thermoplastic modified celluloses for the next future. Regarding environmental considerations, PHA is a promising solution for the paper packaging industry but the problem of material recycling has to be solved and a solution comparable with the recyclability of PE-coated paper packaging products should be obtained.

This review consists of a critical analysis of published results of 1-way food packaging and discusses more in detail what will be necessary for the development of 1-way food packaging based solely on wood derived products and biodegradable polymers.
\end{abstract}

Keywords: paper, packaging, coating, bioplastics, recovery, recycling, fibre

\section{Introduction}

The COST Action FP1003 has already 2 technical review papers published (Johansson et al., 2012; Müller et al., 2014).

The possible topics to be supported by the COST Action FP1003, joint technical paper, is to support and clarify the paper-based packaging possibilities by practical results, practical realisations with values of gas permeability 
(oxygen, $\mathrm{CO}_{2}$ ), water vapour permeability or water transfer rate, defining the recycling possibilities and the resulting environmental impact.

Some time ago we were drinking coffee, enjoying the pleasure of getting a coffee and looking at the coffee cups and a pack of additional biscuits. By regarding more precisely the different components, a combination of paperboard, plastic and aluminium was observed in quite complex structures. Our questions were, how easy is it to recycle these products, what are the reasons for such complex structures, what if petroleum production came to an end and finally, is it possible to use only biobased materials, is it possible to realize such complex packaging structures based solely on wood derived products? Is this already a reality and if not what has to be changed to arrive at completely green solutions? So let's take a more detailed look at these products. Let's take the coffee cups and biscuits packaging as typical examples.

\section{Coffee Cup, an Example of Paper Based Packaging Product}

\subsection{Single-Use Coffe Cups}

When thinking about the properties of single-use coffee cups, we think about drinking coffee without having our hands burned by the hot liquid. So from the consumer point of view the cups basically need to contain the hot coffee for the time required to drink it. That is, to have a cup which have enough mechanical and thermal resistance as well as a low permeability to water (which is the main component of hot coffee). Furthermore, from the producer's point of view, single-use coffee cups also need to be as cheap as possible being a disposable item, and this means they have to be made of materials that are cheap, readily available and easy to process. For these reasons coffee cups are currently made of plastic or more often of paper coated with water resisting materials.

Paper and paperboard are the most widely used packaging materials for both food and non-food products. Because they are composed of highly porous cellulose networks, they readily absorb moisture in high humidity environments or when in contact with liquid or high moisture foods. Therefore they are often coated with hydrophobic coating materials such as polyethylene (PE) to improve their water-resistant properties. One of the major uses of such hydrophobic material coated paperboard is a disposable single-use paper cup with or without a lid. Paper cups were invented a century ago as a cost-effective mean to reduce disease transmission. From that time on, the popularity of these cups has grown constantly and nowadays billions are used each year for hot and cold beverages.

From a technical point of view these cups can be produced using paperboard thatabout $0.2 \mathrm{~mm}$ thick and weights about 150-200 grams per square meter. The plastic materials used for coating must guarantee the water resistance but they also have to be easily processable, heat sealable and resistant to contact with hot acidic fluid, without any chemical leaching of the plastic material or its components into the hot beverages. Polyethylene usually meet all these requirements and thanks to its low price it is one of the most frequently used materials to coat paper and paperboard.

An uncoated paper cup has a high potential for recycling since it is manufactured from $100 \%$ natural pulp, mostly high-quality bleached virgin paperboard; but when coated with the synthetic plastic coating materials such as PE and the less used paraffin wax it is very difficult to separate, recycle, or compost a cup after use. According to the new EN643 standard these products are classified as recyclable in specialized paper mills thus requiring separate collection or sorting from the normal paper grades. Only $13.7 \%$ of the used paper cups are recycled and the remainder is land-filled or incinerated resulting not only in a serious waste of high-valued products but also environmental pollution. Even if we use a paper based cup, therefore is still a lot of space to reduce the environmental impact of such a product.

In this regard there are already some demands when using the recycled paper to make these cups. Regulations limit the amount of recycled paper allowed in the cups; the US FDA allows a maximum of $10 \%$ of recycled paper with a minimum of $90 \%$ of new paper (Timm, 2009). The reason for this limitation is mainly related to the possible risk of food contamination, even if the paper is coated with a layer of plastic material and without direct contact between the beverages and the paper material. Obviously, there is no argument to limit the content of the recycled paper in the production of paper cups coated with a layer of polyethylene, but this is the current regulation, which substantially limit the use of this approach to increase the sustainability of coffee cups.

Another possibility is to use sustainable materials for the coating layer. Since heat sealing of the coating materials is essential for the manufacture of single-use paper cups, any new type of coating material has to possess not only hydrophobic and good film-forming properties but also good heat sealing properties. One of the most promising polymers for this purpose is poly (lactic acid) (PLA) because it is biodegradable, biocompatible, is considered safe for food contact and is already produced on an industrial scale. Therefore, PLA-coated paperboards with good 
water resistance and heat sealing properites can be used for various applications including single-use paper cups. PHAs (poly hydroxyalkanoates) (figure 1) represent a group of biobased polyesters. Poly (hydroxybutyrate) (PHB) and poly(hydroxybutyrate-co-valerate) (PHBV) are the most common PHAs.<smiles>CC(C)C(=O)C(C)OC(=O)C(C)OC(C)C(=O)OC(C)C(=O)O</smiles>

PLA’s chemical structure<smiles>CC(C)CC(C)C(C)OC(C)(C)C</smiles>

PH3B<smiles>CCC(CC(C)C)OC(C)(C)C</smiles><smiles>CCC(CC)CC(=O)OC(=O)CC(C)OC(C)(C)C</smiles>

PHBV

PHV

Figure 1. PHA (poly hydroxyalkanoate) is a family of more than 100 polymers that include poly-3-hydroxyvalerate (PHV), poly-3-hydroxybutyrate (PH3B) and poly-3-hydroxybutyrate-co-3-hydroxyvalerate (PHBV)

A very interesting property of PHAs with respect to food packaging applications is their good water resistance and low water vapour permeability which are close to low-density polyethylene (LDPE). Therefore, PHAs for packaging applications are very promising, especially if the price of these materials further reduces due to an increased production capacity and innovations. However, PHB is characterized by its difficult processability. The difficulties reside in the fact that the melting and decomposition temperatures are practically identical. Hence, stabilizers or blends with other biopolymers and softeners would have to be used.

\subsection{Basic Properties of the Single-Use Coffee Cups Based on Paperboard and Possible Green Solutions}

To understand if such materials can be suitable for the current application we need to consider properties of PE coated paper coffe cups. For example, a paperboard with a weight of $165 \mathrm{~g} / \mathrm{m}^{2}$ can be used for such applications. This paperboard has a thickness around $0.2 \mathrm{~mm}$, a water uptake (Cobb value) after $2 \mathrm{~min}$ of $21.4 \mathrm{~g} / \mathrm{m}^{2}$, a total porosity of $49 \%$ and an open porosity of $6.4 \%$. At $25^{\circ} \mathrm{C}$ and a relative humidity of $50 \%$, the water vapour permeability equals $36.1 \mathrm{~g} \mathrm{~m} /\left(\mathrm{m}^{2}\right.$ day atm) (Rhim \& Kim, 2009), principally related to the porosity of the paperboard. This constitutes the basic layer of the cup giving it satisfactory mechanical properties. This paperboard has to be protected from direct contact with water or hot water for this application. A layer of plastic material with high water resistance, such as polyethylene, PLA or PHA, is usually used on the inner side of the cup.

If this paperboard is coated on one side with a layer of polyethylene that is $30 \mu \mathrm{m}$ thick, the water vapour permeability decreases to $0.075 \mathrm{~g} \mathrm{~m} /\left(\mathrm{m}^{2}\right.$ day atm) (Rhim \& Kim,2009). Roughly, the water vapour permeability is reduced by a factor of 500 and prevents the absorption of water vapour into the paperboard. The water vapour permeability of polyethylene corresponds to a value of $0.01 \mathrm{~g} \mathrm{~m} /\left(\mathrm{m}^{2}\right.$ day atm) while water solubility is as low as 20 ppm $\left(2 \cdot 10^{-3} \%\right.$ by weight) (McCall, 1984). Note that during normal use of a coffee cup, the amount of water penetrated through the polyethylene foil is less than $45 \mathrm{mg}$. The conclusion is that the main role of the polyethylene 
coating is to protect the paperboard against water and that any polymer with good water barrier properties can be used. All these values represent the basic values for further analysis.

If the same paperboard is coated with PLA, as already available on several European markets, with a thickness of $30 \mu \mathrm{m}$ or a coating weight of $60 \mathrm{~g} / \mathrm{m}^{2}$ is needed to obtain the water vapour permeability of $2 \mathrm{~g} \mathrm{~m} /\left(\mathrm{m}^{2} \mathrm{day}\right.$ atm $)$ (Rhim \& Kim,2009). The water vapour permeability of PLA is indeed equal to $0.4 \mathrm{~g} \mathrm{~m} /\left(\mathrm{m}^{2}\right.$ day atm) (Davis, Theryo, Hillmyer, Cairncross, \& Yossef, 2011) or 42.5 times higher than the values for polyethylene and its water solubility can be as high as $1.2 \%$ by weight, but they are perfectly sufficient for this application.

Comparable results to those for the PE-coated drink cups can be also obtained using the PHA-coating. Indeed PHB, which is the most common PHA, has water vapour permeability of about $0.03 \mathrm{~g} \mathrm{~m} /\left(\mathrm{m}^{2}\right.$ day atm) and a liquid water solubility of about $0.02 \mathrm{~g} / \mathrm{g}_{\text {pol }}$ (Miguel \& Iruin, 1996; Kamaev, Iordanskii, \& Startsev, 1999; Shogren, 1997; Khwaldia, Arab-Tehrany, \& Desobry, 2010; Cyras, Soledad \& Analia, 2009), so the properties of these cups will likely be in between those observed for the two previous cups. The water vapour permeability will be approximately the same as that of the PE coated cup while the solubility will be in the range of that observed for PLA and the mechanical properties are quite sufficient for the application.

The coated paperboard can be heat sealed at temperatures higher than the melting temperatures of the polymers, which mens higher than $140^{\circ} \mathrm{C}$ for polyethylene and $160^{\circ} \mathrm{C}$ for PLA. The sealing strength equals $1.2 \mathrm{MPa}$ for the PE-coated paperboard and $4 \mathrm{MPa}$ for the PLA-coated paperboard (Rhim \& Kim,2009), more than sufficient for this application. The high strength is obtained by the flow of the molten polymer into the pores at the surface of the paperboard. The tensile strength of the coated paperboards equals $5 \mathrm{MPa}$ when immersed in water and $35 \mathrm{MPa}$ when water is only in contact with the coated side of the paperboard (comparable to the contact with water in the coffee cup). The paperboards coated with polyethylene or PLA are resistant to temperatures of at least $100^{\circ} \mathrm{C}$. The same temperature resistance can be obtained with poly(hydroxybutyrate-co-valerate) (PHBV) as a coating layer. The melting temperatures of PHBV is between 100 and $180^{\circ} \mathrm{C}$ depending on the composition (McChalicher \& Sctrienc, 2007).

Single-use coffee cups can be regarded as the basis for applications where the water resistance or water vapour permeability is important but there are no specifications regarding the gas permeability, like the oxygen or $\mathrm{CO}_{2}$ permeability. For this kind of application therefore, both the use of PLA or PHAs seems to be suitable and can be classified as a "green" solution to the problem. However the additional layer is still not based on wood derived products and a more attentive analysis has to be performed in order to understand the real sustainability of the so obtained final products.

Apart from this solution then other exists which can still be considered environmental friendly with respect to the original one. For example, PE produced from petroleum can be replaced by the so-called "Green Polyethylene", produced using ethylene obtained from the fermentation of sugarcane. The ethanol produced is further dehydrated at high temperatures over a solid catalyst to produce ethylene. The green PE production reduces the energy consumption in the total cycle by $70 \%$ compared to the cycle (Novaes, 2010) in which oil is converted to petrochemical PE. Green PE is neutral for the global warming effect and does not require any costly alterations to the processing equipment or in final product design. Green PE, especially if the ethylene is used to produce the highly branched polyethylene (LDPE), can replace basically all the applications which currently use fossil-based PE. Obviously this material is not recyclable as the previous biopolymers considered. But the question remains: to what extent are PLA and/or PHA sustainable?

\subsection{Sustainability and Recyclability of Coated Paper Packaging}

When developing new paper based composites, based on renewable biopolymers, aimed at replacing PE some general considerations need to be stated. Pre-consumer production residues can always find their way into a specialised recycling plant whereas post-consumer products often end up in the lower recycled paper grades.

Where do we stand technologically today regarding the sustainability and recycling possibilities of biobased packaging alternatives? Today, practically all the bioplastics market is situated in the food and packaging industry. In general terms; when the packaging product is in direct contact with difficult to remove wet or greasy food then organic recycling in composting plants is very likely the best option whereas for liquid packaging and some other applications material recycling can still be an option provided that product eco-design is well addressed.

Efficient recycling of paper and paper based composite packaging requires (i) good repulpability, (ii) easy mechanical removal of non-paper components, (iii) sufficient fibre yield and low waste rejects, (iv) a small amount of macro and micro "stickies" i.e. compounds derived from adhesives used in constructing the package. Multi-layer paper based products and PE coated paper are presently accepted as special grades in standard EN 643 which defines 
the commercially available recovered paper grades. Nevertheless, it is clear that they must be used in specialised paper mills rather than in standard technology paper mills and they require separate collection or sorting from the normal paper grades. When considering the recycling of paper used in complex new composite paper based packaging, the first option should be the development of a new biopolymer-based approach which does not hamper the paper recycling process. This means that relevant parameters such as repulpability, fibre yield, sticky formation and their potential removal must be assessed in order to avoid major constraints in paper recyclability.This field currently lacks European standard methods, however, some official methods are under development.

One important example (outlined above) is related to the coating layer used in paper and paperboard packaging. The industry standard layer of polyethylene can be replaced by a layer of PLA and the final packaging, such as cups for cold and hot beverages, offers the same or even better functional properties. Most paper cups are designed for a single use and are made of up to $95 \%$ high-strength paper with a 5\% thin coating of plastic. The global warming effect for polyethylene equals $2.1 \mathrm{~kg} \mathrm{CO} 2$,eq $/ \mathrm{kg}$, for PLA is $1.3 \mathrm{~kg} \mathrm{CO}_{2, \mathrm{eq}} / \mathrm{kg}$ and for the paperboard it is $1.8 \mathrm{~kg} \mathrm{CO}_{2, \text { eq }} / \mathrm{kg}$ (Vink, Davies \& Kolsrad, 2010). By replacing polyethylene with PLA a small reduction equal to of $2 \%$ of global warming is obtained. This effect is quite small and other advantages of using PLA in the coating layer are necessary for PLA to be adopted as a coating layer. These advantages must relate to the recyclability and/or degradability of these bioplastics.

For efficient recyclability, the new, green coffee cups must be easy to separate into the different basic components, such as the PLA and the paper using water if possible, perhaps under strong alkaline conditions at optimized temperatures. This makes it possible to recycle the bioplastics and the paper separately and if possible, reuse it in the same application. The gain of products can be important regarding the following example. The production of 16 billion paper cups, equal to $8010^{6} \mathrm{~kg}$ of coffee cups, needs $15000000 \mathrm{~m}^{3}$ of water and produces $12510^{6} \mathrm{~kg}$ of waste (Hocking, 1994). By recycling, there is not only the gain in basic products but the global warming effect and water consumption are also going down. For example, the emission is going down from $15 \mathrm{~kg} \mathrm{CO}_{2 \text {,eq }}$ for 1000 coffee cups to a value of $7 \mathrm{~kg} \mathrm{CO}_{2, \text { eq }}$ by recycling the different products for the same application or even by using the recycled products for other applications. These gains result from 2.4 times less energy consumption together with a 6.2 times less water consumption (Hocking, 1994).

The basic paper or paperboard layer is coated and protected from direct contact with the beverages. There seems no direct reason to limit the content of the recycled paper to a maximum of $10 \%$. In the limit, $100 \%$ of recycled paper can be used for the basic paperboard layer thus creating more sustainable solutions for these cups. Only the contamination caused by food and drinks can limit the recyclability of the paper for packaging solutions with food contact. Preferably, if lids are used they will be produced from the same polymer as the one used for the coated layer. This will be of great advantage for the recyclability of the total structure.

Recycling is not as straightforward as one may think because the cups contain paper and plastic. This composite structure and collection and reclamation processes make the recycling of this growing environmental concern challenging. Not only is the presence of different materials a challenge for recycling, but inks are a problem. Concerning the inks, an interesting field of interest is the research and development of non-toxic and/or renewable inks. All these materials need to be considered in the recycling process and when designing the cups for recyclability. Annually, over 220 billion disposable paper cups, equal to $110010^{6} \mathrm{~kg}$, are used worldwide (Smithers, 2013). Contamination caused by food, drinks, inks and mineral oils can limit the recyclability of the paper and the small amount of plastic (5\%) which coats the paper prevents most paper mills from accepting PE-coated cups for recycling because plastic can contaminate the downstream processes in many paper mills. According to a press release in the UK, for a paper mill to begin recycling paper cups, at least 10 tons of used paper cups are needed monthly, that's almost 2 million cups a month (Smithers, 2013). For disposable cup recycling to become a reality, the used cups need to be collected systematically in bulk.

A possible recycling process involves softening the cup waste in a warm aqueous solution and separating the plastic coating from the fibers by floatation. The plastic is skimmed off, pulverized and recycled, leaving water and pulp together with possible impurities such as inks. A great advantage of PE in the recycling process is its density, around $920 \mathrm{~kg} / \mathrm{m}^{3}$ (Sinh, Upadhyaya, Chand, \& Mishra, 2012). The PE film floats on the surface of the water bath and can be separated easily from the rest. This is not the case wtih the bio-polymers such as PLA, PHA and others, because their density is higher than that of water (Sinh, Upadhyaya, Chand, \& Mishra, 2012). The films from these bio-polymers sink to the bottom of the water bath, making it difficult to separate them from the pulp. This is a serious disadvantage of the bio-polymers. If the paper cups can be recycled into their components, paper and plastic, the best solution is to use a polymer with a density lower than that of water. 
What about the ink pigments and oils due to the printing on the outher surface of paper cups? The possible solution to this is not to print directly on the paperboard but to use a sleeve of printed plastic crimped around the paper cups. This sleeve would be mechanically attached to the paper cups (crimped around the cups) and can easily be separated afterwards from the paper cups, by simply cutting it. The polymer used for these sleeves can be the same polymer as the internal film or completely different because its separated from the paper cups before their treatment in the warmed aqueous solution. The use of biopolymers such as PLA or PHA may be the most interesting solution.

\subsection{Organic Recyclability of Coated Paper Packaging Solutions}

Plastic-coated paper packaging products end their life in composting facilities, incinerators, landfills or are dispersed into the environment. In the environment, the oil-based plastics do not appear to biodegrade or their biodegradation is extremely slow. Especially, the crystalline domains of the polymers, such as polyethylene and other petroleum-based polymers, are resistant to biodegradation and may give rise to nanoparticles which might persist for a long time and are impossible to clean up (Webb, Arnott, Crawford, \& Ivanova, 2013). Hence, they are suspected of causing detrimental effects to organisms in a variety of ecosystems (Andrady, 2011). They are a great problem in the oceans forming large islands of non-biodegradable plastics (Andrady, 2011). Composting facilities may exclude plastic-coated paper products from their guidelines to prevent future harm. Up to now, there is no direct method for determining whether a paper product is coated with a petroleum-based plastic. Therefore, companies will have to use a well-defined method for the certification of compostable products - EN13432 when developing bio-plastic coated paper products to claim compostability.

Paper cups coated with a bio-plastic such as PLA or PHA do not become trash but become compost. Nonetheless, a PLA-coated cup will not degrade in any backyard compost bin; it needs the carefully controlled decomposition environment of a commercial or municipal compost facility, otherwise it will pollute just as much as any other non-degradable cup. The key to the future success of bioplastic-coated paper cups dependents highly on the development of full biodegradability under normal environmental conditions and in the limit, not creating nanoparticles or islands in the oceans. When it comes to paper packaging applications, a truly recyclable cup is on the horizon, but its success will depend on paper mills' willingness to accept and recycle them.

The problem of polymeric micro- or nanoparticles arises from their resistance toward biodegradation as a result of their physical structure. A number of studies have established a link between plastic degradability and the degree of crystallization of the polymers (Kint \& Munoz-Guerra, 1999; Kondratowicz \& Ykielski, 2009; Marten, Müller, \& Deckwer, 2003; Müller, 2006). Increased crystallization decreases the availability of polymer chains to degradative agents, such as microbial lipases or other ester lysing molecules for biopolymers. Evidence for this can be seen in the lipase-catalyzed degradation of poly(hydroxybutyrate-co-valerate) (PHBV) which occurs preferentially in the amorphous regions, exposing the polymer crystal (Herzog, Müller\& Deckwer, 2006). As such, amorphous bio-polymers represent a better solution to avoiding the formation of polymeric micro- or nanoparticles in the environment. The slower degradation of plastics in sea water is primarily the result of relatively lower temperatures and the lower oxygen concentration in water. The difference between the degradation rates in air and sea water can be exacerbated by fouling effects.

For example, PHA-coated paper was subjected to marine biodegradation tests. Paper bags and PHA were tested for their biodegradation in marine conditions and it was found that PHA biodegrades significantly quicker than a paper bag. After 10 days, the paper bag was only $10 \%$ biodegraded versus $50 \%$ for PHA (Whitman, 2010). After 90 days, the paper bag was $40 \%$ biodegraded versus $75 \%$ for PHA. The presence or formation of micro- or nanoparticles was not studied or mentioned in these experiments, which may mean that the $25 \%$ of PHA which is not biodegraded is still present in the marine environment as nanoparticles. Consequently further research is necessary to fully understand the marine biodegradation of bio-plastics. In other experiments, the results show that PHA samples were biodegraded between 52 and 82 percent after 12 months in a simulated marine environment at $30^{\circ} \mathrm{C}$. The differences were largely influenced by the composition and degree of crystallinity and appear comparable to the cellulose (paper) samples which were biodegraded by 52 percent. After 12 months of testing, only 8 percent of PLA and 6 percent of polyethylene (LDPE) were biodegraded (Kondratowicz \& Ykielski, 2009).

It is expected that paper and paper board will remain an important biobased packaging material due to their excellent mechanical properties. Today, the paper-based materials are coated with a thin layer of a petroleum derived plastic, mostly polyethylene, which has provided the cups and other packaging solutions with the required barrier property and water resistance. Paper-based packaging products coated with PE are readily repulpable as the hydrophobic PE is easily removed in the pulping process. Hence, the ongoing challenge is to coat the paper with a 
biobased, hydrophobic polymeric material which must be repulpable or otherwise biodegradable in most of the environments considered.

\subsection{Layer With Low Gas Permeability, Example of the Biscuits}

Let us return to the example of the biscuits. By visual inspection of the packaging, a metallised layer and a plastic layer can be seen. Further analysis of this packaging material confirms this observation and the final result of this analysis is a laminated structure comprising a metallised polyester and a layer of polyethylene. What are the reasons for that? Biscuits are sensitive to water or humidity which requires the use of highly water-vapour impermeable packaging. In addition to this, the packaging material should also be fat resistant, rigid, with very low oxygen permeability and must be sealable. The main criteria for such packaging are thus low gas permeability, high water-vapour barrier, a good grease barrier and sealability. Often, a good oxygen barrier is commonly also a good grease barrier and can regarded as one common property. The question is, can a barrier layer based on cellulose or starch be used for such high demand packaging applications?

The majority of current packaging materials are produced from fossil-derived plastics. Even fibre-based packaging solutions usually incorporate one or more layers of synthetic polymers to provide reliable barrier properties to the packaging, as already mentioned for the coffee cups. Microfibrillated cellulose, or MFC, is a biodegradable film-forming material widely studied for its industrially interesting properties and possible applications in food packaging. Films made from MFC may be used for the preparation of multifunctional barriers. MFC is produced from sustainable cellulose resources, and due to the relatively high crystallinity, it has excellent oxygen barrier properties under dry conditions. MFCs are being investigated for use as a coating layer on paper substrates in order to improve barrier properties and reduce surface porosity. They are known to be an effective barrier to gas transport $\left(\mathrm{O}_{2}, \mathrm{CO}_{2}\right)$, although they are very permable to water vapour. Several studies have shown that MFC may be successfully used as a barrier in paper coating. However, a coating with MFC requires a very high water content and thus a high quantity of energy to dry. Coating MFC films with higher water barrier polymers could possibly improve barrier properties and also other benefits.

For most practical applications, an oxygen permeability of 10 to $20 \mathrm{~cm}^{3} /\left(\mathrm{m}^{2}\right.$ day atm) is sufficient. Under dry conditions, the oxygen permeability of MFC is close to $54 \mathrm{~cm}^{3} \cdot \mu \mathrm{m} /\left(\mathrm{m}^{2}\right.$ day atm $), 0.6$ for the carboxylated MFC (cMFC) and 0.08 for neutralised carboxylated MFC (CMFC-COONa) (Aulin, GÄllstedt\& Lindström, 2010). At a relative humidity of 50\%, MFC absorbs between 4 and $5 \mathrm{wt} \%$ water, the carboxylated MFCs absorb between 10 and $12 \mathrm{wt} \%$ water and the oxygen permeability is increased for all the different MFC's to a value of 200 $\mathrm{cm}^{3} . \mu \mathrm{m} /\left(\mathrm{m}^{2}\right.$ day atm) (Syverud \& Stenius, 2009; Siro \& Plackett, 2010). This means that a coating layer with a thickness between 10 and $20 \mu \mathrm{m}$ is necessary for most practical applications. In direct contact with water, the water absorption increases to values of $10 \mathrm{wt} \%$ for MFC and to $45 \mathrm{wt} \%$ for all the carboxylated MFCs. As a conclusion, a good oxygen or $\mathrm{CO}_{2}$ barrier can be obtained with the coated layers based on MFC if these layers are kept dry or protected from direct contact with water.

The combination of MFC and paper is relatively new and only a few scientific publications have addressed this theme (Rodionova, Lenes, Eriksen, \& Grgersen, 2011; Pawar \& Purwar, 2013; Babu, O'Connor, \& Seeram, 2013). MFC may well succeed in improving the mechanical and barrier properties of paper, and the first studies have reused interest in applying this combination in the fields such as food packaging and printing.

The water vapour transmission rate (WVTR), i.e., the mass of water vapour passing through a film per unit area and time under specific conditions, and water vapour permeability (WVP) were the first barrier properties of MFC films to be studied. One objective was to use these films in barrier packaging to replace the modified atmosphere packaging (MAP) materials that are currently in use. The results were observed were dependent upon different parameters, such as the sources of MFC, the production treatment and chemical modifications of MFC.

The water vapour permeability is strongly affected by the water absorption of the MFC films. In the limit, under dry conditions, the WVP reaches a value of $0.015 \mathrm{~g} \mathrm{~m} /\left(\mathrm{m}^{2}\right.$ day atm), increasing to a value of 0.4 at $50 \%$ relative humidity and reaching a value of 10000 in direct contact with water (Aulin, Gällstedt \& Lindström, 2010). For comparison, the WVP of polyethylene equals $0.01 \mathrm{~g} \mathrm{~m} /\left(\mathrm{m}^{2}\right.$ day atm) and PLA is of the order of $0.4 \mathrm{~g} \mathrm{~m} /\left(\mathrm{m}^{2}\right.$ day $\mathrm{atm}$ ) and these polymers are not sensitive to humid atmospheres. Due to their hydrophilic nature, MFC films are sensitive to water. Therefore, it is necessary to protect the MFC layer with a layer of water-insensitive polymer in order to overcome this drawback. An MFC coating thus presents a major field of interest to improve the barrier properties of materials and can be sufficient if the relative humidity is limited to $60 \%$. 


\section{Discussion}

MFC could indeed be the answer to society's requirements for improved packaging. Its renewability makes it a subject of intense interest as an alternative material. Its biodegradability offers a response to environmental laws and waste management problems. Finally, its barrier property reinforcement offers superior protection and preservation of products, and could thus help to improve the shelf-life of food. The MFC-films have a lot of potentially interesting properties but the sensitivity to water or the relative humidity around those films is a major concern for packaging applications. The films must be protected from water or moisture and the films cannot be heat sealed. So, other layers surrounding the MFC films are necessary for practical packaging applications.

One of the possibilities to protect MFC films from humidity or water contact is to coat the films with a layer of a bio-polymer such as PLA or PHA on one or both sides of the MFC depending on the application. Practical results are necessary to confirm that the performance of PLA or PHA is good enough as water moisture barrier for the MFC films. Once again, the problem of compatibility between the different polymers arises because the bio-polymers are not compatible with MFCs. The possibility of promoting good cohesion between the layers produced from these different products requires the bio-polymers or Green PE to be modified with maleic anhydride, producing maleic acid grafted products. The chemical reaction taking place in the molten state between the grafted maleic acids and the hydroxyl groups of the cellulose creates the necessary links for a very good adhesion between the different layers. A paper layer can be coated on one or both sides with a layer of MFC and both sides of this complex structure are finally coated with a MA-grafted PE, industrially produced on a large scale, or with a MA-grafted PHA or PLA, neither of which are currently on the market.

\section{Conclusion}

Many interesting developments are already known for the manufacturing of cellulose-based products, such as MFC's or modified celluloses, usable in the paper packaging industry. Paper and paperboard in combination with Green-PE, MFC's and PHAs seems to be the most promising solution for the packaging industry in the near future and the development of the thermoplastic modified celluloses for the next future.

Green-PE, especially if this has the structure as the low density polyethylene (LDPE), can replace directly all the applications currently using fossil-based PE. The PHAs are still more difficult to process but has the advantage to be biodegradable. The modified celluloses seems the most interesting products for the future but there is still a lot of research required before the development of theire use in 1-way biobased food applications.

Regarding environmental considerations, PHA is a better solution than PLA for the paper packaging industry but the problem of material recycling has to be solved and a solution comparable with the recyclability of PE-coated paper packaging products should be obtained.

For the next future, there is a need for cellulose-based feedstocks for the production of biopolymers and expanding the current bio-based industry which is focused on making bio-versions of existing monomers and polymers. Currently, renewable feedstocks used for producing bio-based monomers and polymers often compete with requirements for food-based products. Further research is necessary for the production of usable sugars from cellulose-based feedstocks for the production of biopolymers.

\section{Acknowledgments}

The European Cooperation in the Field of Scientific and Technical research, COST Action FP1003: Impact of renewable materials in packaging for sustainability - development of renewable fibre and bio-based materials for new packaging applications, is thanked for providing the opportunity to perform this article.

\section{References}

Andrady, A. L. (2011). Microplastics in the marine environment. Marine Pollution Bulletin, 62(8), 1596-1605, http://dx.doi.org./10.106/marpolbul.2011.05.030

Aulin, C., Gällstedt, M., \& Lindström, T. (2010). Oxygen and oil barrier properties of microfibrillated cellulose films and coatings. Cellulose, 17, 559-574, http://dx.doi.org./10.1007/s10570-009-9393-y

Babu, R. P., O'Connor, K., \& Seeram, R. (2013). Current progress on bio-based polymers and their future trends. A review paper. Progress in Biomaterials, 2(8), 16. http://dx.doi.org./10.1186/2194-0517-2-8

Cyras, V. P., Soledad, C. M., \& Analia, V. (2009). Biocomposites based on renewable resource: Acetylated and non-acetylated cellulose cardboard coated with polyhydroxybutyrate. Polymer, 50(26), 6274-6280, http://dx.doi.org./j.polymer.2009.10.065 
Davis, E. M., Theryo, G., Hillmyer, M. A., Cairncross, R. A., \& Yossef, A. (2011). Liquid Water Transport in Polylactide Homo and graft Copolymers. ACS Applied Material Interfaces, 3(10), 3997-4006, http://dx.doi.org./10.1021/am2008618.Epub2011 Sep21

Herzog, K., Müller, R. J., \& Deckwer, W. D. (2006). Mechanism and kinetics of the enzymatic hydrolysis of polyester nanoparticles by lipases. Polymer Degradation and Stability, 91, 2486-2498, http://dx.doi.org./10.106/j.polymdegradstab.2006.03.005

Hocking, M. B. (1994). Reusable and disposable cups: An energy-based evaluation. Environmental Magazine, 18(6), 889-899. http://dx.doi.org./10.1007/BF02393618

Johansson, C., Bras, J., Mondragon, I., Nechita, P., Plackett, D., Simon, P., ... Aucejo, S. (2012). Renewable fibers and bio-based materials for packaging applications- a review of recent developments. BioResources, 7(2), 2506-2552. http://dx.doi.org./10.15376/biores.7.2.2506-2552

Kamaev, P., Iordanskii, A., \& Startsev, O. (1999). Study of the kinetics of water sorption by biocompatible poly (3-hydroxybutyrate) membranes, Pharmaceutical Chemistry Journal, 33(1), 49-51. http://dx.doi.org./10.1007/BF02508417

Khwaldia, K., Arab-Tehrany, E., \& Desobry, S. (2010). Biopolymer coatings on Paper Packaging Materials. Comprehensive Reviews in Food Science and Food Safety, 9(1), 82-91, http://dx.doi.org./10.1111/j. 1541-4337.2009.00095.x

Kint, D., \& Munoz-Guerra, S. (1999), A review on the potential biodegradability of poly(ethylene terephtalate). Polymer International, 48(5), 346-352, http://dx.doi.org./10.1002/(SICI)1097-0126(199905)

Kondratowicz, F. L., \& Ykielski, R. (2009). Synthesis and hydrolytic degradation of poly(ethylene succinate) and poly(ethylene terephtalate) copolymers. Polymer Degradation and Stability, 94, 375-382, http://dx.doi.org./10.1016/j.polymdegradstab.2008.12.001

Marten, E., Müller, R. J., \& Deckwer, W. D. (2003). Studies on the enzymatic hydrolysis of polyesters I. Low molecular mass model esters and aliphatic polyesters, Polymer Degradation and Stability, 80(3), 485-501, http://dx.doi.org./10.1016/S0141-3910(03)00032-6

McCall, D. W., Douglass, D. C., Blyler, L. L., Johnson, G. E., Jelinski, L. W., \& Blair, H. E. (1984). Solubility and Diffusion of Water in Low-Density Polyethylene. Macromolecules, 17(9), 1644-1649, http://dx.doi.org./10.1021/ma00139a002

McChalicher, C. W., \& Srienc, F. (2007). Investigating the structure-property relationship of bacterial PHA block copolymers. Journal of biotechnology, 132(3), 296-302. http://dx.doi.org./10.1016/j.biotec.2007.04.014

Miguel, O., \& Iruin, J. J. (1996). Survey on Transport Properties of Liquids, Vapors and Grases in Biodegradable Poly (3-hydroxybutyrate) (PHB). Journal of Applied Polymer Science, 64(9), 1849-1859, http://dx.doi.org./10.1002/(SICI)1097-4628(19970531)64:9<1849:AID-APP22>3.0.CO;2-R

Müller, G., Hanecker, E., Blasius, K., Seidemann, C., Tempel, L., Sadocco, P., ... Bobu, E. (2014). End-of-life solutions for Fibre and Bio-based Packaging Materials in Europe, Packaging Technology and Science, 27(1), 1-15. http://dx.doi.org./10.1002/pts.2006

Müller, R. J. (2006). Biological degradation of synthetic polyesters-enzymes as potential catalysts for polyester recycling. Process Biochemistry, 41(10), 2124-2128. http://dx.doi.org./10.1016/j.procbio.2006.05.018

Novaes, L. (2010). Green polyethylene bringing renewable raw materials to the traditional plastic industry". TAPPI conference, Albuquerque, New Mexico USA, April 18-21, 2010

Pawar, P. A., \& Purwar, A. H. (2013). Biodegradable Polymers in Food Packaging. American Journal of Engineering Research, 2(5), 151-164.

Rhim, J. W., \& Kim, J. H. (2009). Properties of Poly(lactide)-coated Paperboard for the use of 1-way Paper cup. Journal of Food Science, 74(2), E105-E111, http://dx.doi.org./10.1111/j.1750-3841.2009.01073.x

Rodionova, G., Lenes, M., Eriksen, O., \& Gregersen, O. (2011). Surface modification of Microfibrillated cellulose: improvement of barrier properties for packaging applications. Cellulose, 18, 127-134, http://dx.doi.org./10.1007/s10570-010-9474-y

Shogren, R. (1997). Water vapor permeability of biodegradable polymers. Journal of Environmental Polymer Degradation, 5(2), 91-95, http://dx.doi.org./10.1007/2FBF02763592 
Singh, O., Upadhyaya, P., Chand, N., \& Mishra, T. K. (2012). Mechanical and optical properties of Poly Lactic Acid modified Linear-Low Density Polyethylene/Low Density Polyethylene (LLDPE/LDPE) blend blown film. International Journal of Mechanical and Industrial Engineering, 2(1), 11-14

Siro, I., \& Plackett, D. (2010). Microfibrillated cellulose and new nanocomposite materials : a review. Cellulose, 17, 459-494, http://dx.doi.org./10.1007/s10570-010-9405-y

Smithers, R. (2013). British company James Cropper PLC develops technology to recycle disposable coffe cups, The Guardian. Wednesday 17 july 2013.

Syverud, K., \& Stenius, P. (2009). Strength and barrier properties of MFC films. Cellulose, 16, 75-85. http://dx.doi.org/10.1007/s10570-008-9244-2

Timm, B. (2005). Sustainabilty: A success strategy at Starbucks. Green@work, Jul/Aug 2005.

Vink, E. T. H., Davies, S., \& Kolstad, J. J. (2010). The eco-profile for current Ingeo polylactide production, Industrial Biotechnology, 6(4), 212-224. http://dx.doi.org./10.1089/ind.2010.6.212

Webb, H. K., Arnott, J., Crawford, R. J., \& Ivanova, E. P. (2013). Plastic degradation and Its Environmental Implications with special reference to Poly(ethylene terephthalate), A Review. Polymers, 5(1), 1-18. http://dx.doi.org./10.3390/polym501001

Whitman, J. (2010). Taking marine biodegradable mainstream. The U.S. Navy's Energy and Environmental Magazine, Currents, Winter 2010 Issue, 54-57.

\section{Copyrights}

Copyright for this article is retained by the author(s), with first publication rights granted to the journal.

This is an open-access article distributed under the terms and conditions of the Creative Commons Attribution license (http://creativecommons.org/licenses/by/3.0/). 